\title{
A collaborative community approach to adolescent substance misuse in Iceland
}

\author{
Inga Dora Sigfusdottir PhD, ${ }^{1,2}$ Alfgeir L. Kristjansson $\mathrm{PhD},{ }^{1,2}$ \\ Margret L. Gudmunsdottir MA ${ }^{1}$ and John P. Allegrante PhD ${ }^{1,2,3}$
}

\author{
${ }^{1}$ Icelandic Centre for Social Research and Analysis, Reykjavik University, Iceland, email ingadora@ru.is; \\ ${ }^{2}$ Department of Health and Behavior Studies, Teachers College, Columbia University; \\ ${ }^{3}$ Department of Sociomedical Sciences, Mailman School of Public Health, Columbia University, New York, USA
}

\begin{abstract}
Cubstance use has become a major threat to health and human development in many European countries. In 23 out of 28 countries participating in the European School Survey Project on Alcohol and Other Drugs (ESPAD), there was a constant and substantial increase in substance use among secondary-school students between the years 1995 and 2003 (Hibell et al, 2003). Iceland experienced a similar upward trend in substance use (Sigfusdottir et al, 2008). Throughout the 1990s, the use of alcohol, tobacco and other drugs increased steadily among $15-$ and 16 year-olds. In 1998, approximately $17 \%$ of 16 -year-olds had tried hashish, which was the highest frequency to be measured in Iceland, and over $80 \%$ reported that they had used alcohol once or more in their lives (Thorlindsson et al, 1998).

In spite of prevention efforts being employed at the time, which mainly focused on educating adolescents about the negative health effects of substance use and was mostly carried out within schools, use of substances was increasing. At this point, we decided to try a new approach to prevention: a collaborative method that focused on youth behaviour. For the past decade, an interdisciplinary group of social scientists, policy makers and practitioners interested in youth development has made an effort to understand what predicts adolescent behaviour. We work closely with various governmental and non-governmental organisations and, with their support, a number of comprehensive studies have been done, focusing on the health and well-being of adolescents, their lifestyle, behaviour and delinquency. Based on the findings, an evidence-based policy has been devised and developed to reduce known risk factors and strengthen a broad range of community-level protective factors.
\end{abstract}

\section{The earlier approach}

For decades, adolescent substance use prevention in Iceland focused on educating adolescents about the negative consequences of substance use. Most of these educational programmes were carried out and evaluated within separate community spheres and thus failed to foster the necessary collaboration between schools and other community stakeholders that might have led to a common set of understandings about the multilevel aetiology of substance use. Schools and youth organisations, working in isolation, failed to produce the kind of shared conceptual framework that characterises transdisciplinary approaches (Rosenfield, 1992), from which local authorities might have more successfully addressed the potentially modifiable factors underlying substance use. Finally, prevention efforts were not grounded in social science theory, nor had they used empirical research and the available evidence base on substance use prevention (Saxe et al, 2006).

\section{The current approach}

Our current work has been guided by key theories from social science, including Durkheim's work on social integration and regulation (Durkheim, 1897). Although Durkheim focused on suicide and social deviance, his theoretical perspective on human behaviour and social problems has a broad and enduring conceptual scope. It covers critical variables related to the family, the school and other social institutions that are readily applicable to many contemporary social problems, including substance use. Durkheim emphasised that weak social integration can lead to social problems and reduced individual well-being. Thus, individuals experiencing insufficient social control and social support are more likely than well-integrated individuals to engage in delinquent acts. In line with Durkheim's theory, as well as Hirchi's (1969) control theory, our annual surveys (see below) of all adolescents in secondary schools in Iceland have shown that those who are better attached to their parents are likely to experience greater social control over their behaviour than those who are poorly attached. Further, individuals with weak attachment bonds experience fewer social controls over their behaviour, thus enabling them to engage in delinquent behaviour such as substance use. These theories, along with Coleman's (1998) theory on social capital, provide the theoretical foundation on which Iceland's adolescent substance use prevention policy and practice have been based for over a decade.

Consistent with systems-based public health (Yarnell, 2007), Iceland's approach to adolescent substance use is primary prevention. We seek to curtail the initiation of substance use before any signs of experimentation are evident.

\section{Surveys and intervention}

Figure 1 shows the substance use rate among two age cohorts, one born in 1984 and another born in 1991. It reveals different trends for the two. Adolescents in a cohort who reported above-average use of any substance at the age of 13 maintained its high use through to the next 2 years and used substances heavily at the age of 15 . However, 


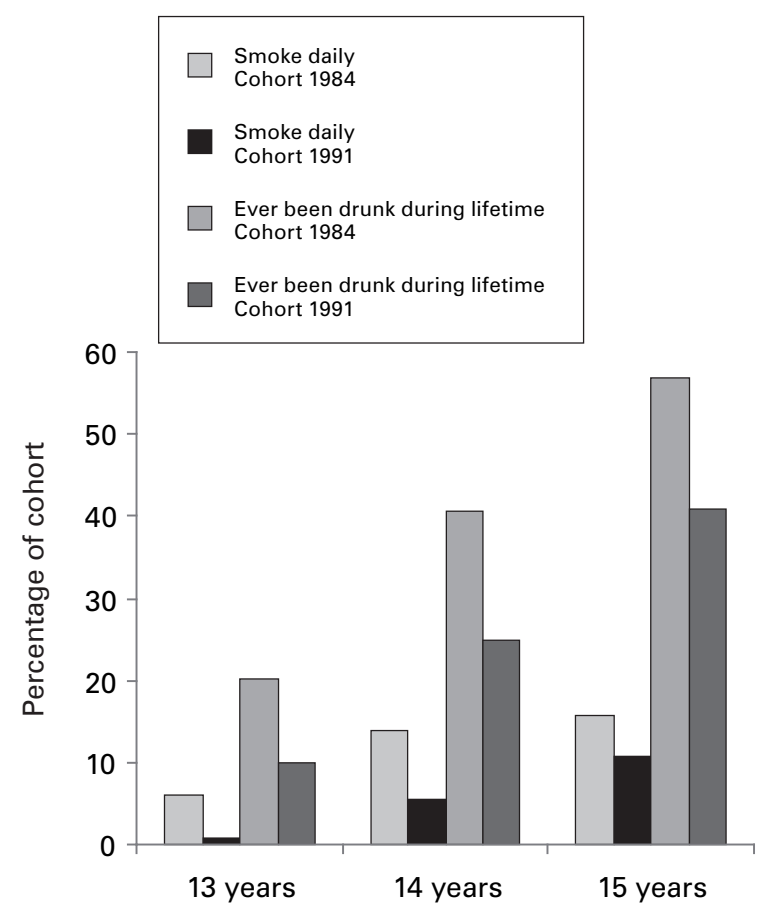

Fig. 1 Percentages of community respondents who reported ever being drunk (in lifetime) and daily smoking: cohorts born in 1984 and 1991, at ages 13, 14 and 15 years.

13-year-olds who reported little substance use continued to engage in relatively low use through the next 2 years.

In line with these findings, we tried to identify and reach adolescents early in their formative school years, as well as the parents of younger adolescents, in order to intervene at the developmentally critical stage before substance use is adopted. Thus, understanding the major peer and social influences in the lives of adolescents is essential to strengthening those protective factors and decreasing those risk factors that become the priority for intervention.

The intervention uses the concepts and processes suggested by traditional planning models. First, our annual survey data provide iterative cycles of evidence that are necessary to monitor annual changes in both risk and protective factors, as well as in alcohol, tobacco and cannabis use in each community. This permits us to compare changes over time within the Icelandic community in general and with other countries. Second, our presentations of these data to the community provide local stakeholders with an opportunity to reflect on what the data say about youth behaviour in their community. Finally, the community-level input about the practical means by which any given community may contribute to the work of prevention has enabled us to recommend actions that are likely to be owned, implemented and sustained by local communities. Informed by the data, we are able to propose and facilitate action across multiple sites and at multiple levels. As new data from our surveys emerge and are periodically reviewed by participants to assess process and outcome dimensions of the intervention, local authorities work with us to make adjustments in programming to ensure the continued relevance of the approach.

By studying the findings from our annual surveys and comparing them with those of studies carried out in other countries, we have achieved good results.

\section{Results}

\section{Substance use declined}

The proportion of tenth-graders who reported becoming drunk during the past 30 days decreased from $42 \%$ in 1998 to $20 \%$ in 2007 . Also, the proportion of tenth-graders who reported smoking cigarettes daily was $23 \%$ in 1998 but fell to $10 \%$ in 2007 . Furthermore, the proportion of adolescents who had ever used hashish in their lives decreased from 17\% in 1998 to an all-time low of $7 \%$ in 2007.

\section{Trends in risk and protective factors changed}

Changes in many risk and protective factors for adolescent substance use have been clear and consistent. For example, the proportion of adolescents reporting that their parents monitored with whom they were spending time in the evenings was 49\% in 1997, compared with 67\% in 2006.

\section{Binge drinking and incidents related to drinking decreased in ranking across Europe}

When findings from the ESPAD studies in 1995 and 2003 are compared, Icelandic tenth-graders moved in the ranking of adolescents' binge drinking and serious incidents related to drinking from being among the highest to well down into the middle (Hibell et al, 2003).

\section{Community comparison}

Although substance use among Icelandic adolescents in general decreased over the period, the decrease was significantly larger in those local communities that used our methods than in other communities (Kristjansson et al, 2010).

\section{Discussion}

Adolescents spend their lives predominantly within the domains of parents and family, the school, the peer group, and in leisure activities, as well as within the larger social milieu of their local communities. It is in these social circumstances that adolescent substance use occurs (Thorlindsson et al, 1998). Although the onset of substance use usually emerges in the peer group, risk and protective factors can be found in all domains of adolescent lives. Furthermore, these domains intersect and influence each other in complex ways that place young people at risk for health-compromising behaviours.

Our primary prevention approach focuses on adolescent health promotion in both the school and broader (community-wide) settings (Sigfusdottir et al, 2009). Moreover, our approach is based on social science theory, which links community-level mobilisation to individual behaviour, coupled with an institutionalised capacity for collecting populationbased data; this has yielded a rich, dynamic and nuanced picture of the potentially modifiable risk and protective factors at the individual, family, community and societal levels.

The core elements of the approach include:

o utilising evidence-based understanding of the risk and community-level protective factors to inform intervention

$O$ an intervention approach designed to be communitybased and responsive to these two sets of factors

$O$ an emphasis on building collaboration between researchers, policy makers and practitioners at the community level. 


\title{
References
}

Coleman, J. (1998) Social capital in the creation of human capital. American Journal of Sociology, 94 (suppl.), 95-120.

Durkheim, E. (1897) Suicide. Free Press (1951).

Hibell, B., Barbro, A., Bjarnason, T., et al (2003) The ESPAD Report 2003. Alcohol and Other Drug Use Among Students in 26 European Countries. Swedish Council for Information on Alcohol and Other Drugs (CAN) and the Pompidou Group at the Council of Europe.

Hirchi, T. (1969) Causes of Delinquency. University of California Press.

Kristjansson, A. L., James, J. E., Allegrante, J. P., et al (2010) Adolescent substance use, parental monitoring, and leisure-time activities: 12-year outcomes of primary prevention in Iceland. Preventive Medicine, 51, 168-171.

Rosenfield, P. L. (1992) The potential of transdisciplinary research for sustaining and extending linkages between the health and social sciences. Social Science and Medicine, 35, 1343-1357
Saxe, L., Kadushin, C., Tighe, E., et al (2006) Community-based prevention programs in the war on drugs: findings from the 'Fighting back' demonstration. Journal of Drug Issues, 36, 263-293.

Sigfusdottir, I. D., Kristjansson, A. L., Thorlindsson, T., et al (2008) Trends in prevalence of substance use among Icelandic adolescents, 1995-2006. Substance Abuse Treatment Prevention and Policy, 3, 12

Sigfusdottir, I. D., Thorlindsson, T., Kristjansson, A. L., et al (2009) Substance use prevention for adolescents: the Icelandic model. Health Promotion International, 24, 16-25.

Thorlindsson, T., Sigfusdottir, I. D., Bernburg, J. G., et al (1998) Vímuefnaneysla ungs fólks: Umhverfi og aðstæður [Substance Use Among Young People.] Rannsóknarstofnun uppeldis-og menntamála.

Yarnell, J. W. G. (2007) Epidemiology and Prevention: A System-Based Approach. Oxford University Press.

\section{Mental healthcare in the Slovak Republic: current situation and future challenges}

\author{
Jozef Dragašek MD PhD ${ }^{1}$ and Alexander Nawka MD² \\ 11st Department of Psychiatry, Faculty of Medicine, University of P. J. Safarik, Košice, Slovak Republic, email jozef.dragasek@upjs.sk \\ ${ }^{2}$ Department of Psychiatry, 1st Faculty of Medicine, Charles University, Prague, Czech Republic
}

\begin{abstract}
- he Slovak Republic is a landlocked country in central Europe with a population of over 5 million. The Czech Republic and Austria lie to the west, Poland to the north, Ukraine to the east and Hungary to the south. The largest city is the capital, Bratislava; the second largest city is Košice. Slovakia is a member of the European Union, the United Nations, the Organisation for Economic Cooperation and Development (OECD) and the World Trade Organization, among other international organisations. The majority of the inhabitants of Slovakia are ethnically Slovak (85.8\%). Hungarians are the largest ethnic minority (9.5\%). With a gross domestic product (GDP) of $€ 63.3$ billion in 2009, Slovakia is classified as a middle-income country. In that year total health expenditure represented $6.7 \%$ of GDP (Pažitný, 2008), 34\% of which went on pharmaceuticals, the highest share among all OECD countries (World Health Organization, 2010).
\end{abstract}

\section{Prevalence of mental disorders}

Two epidemiological studies have recently been conducted to assess the prevalence of depressive and anxiety disorders in Slovakia - the EPID (Heretik et al, 2003) and EPIA (Novotný et al, 2006) surveys. According to the EPID survey, the 6-month prevalence rate of depression is $41 \%$ ( $13 \%$ major depression, $5 \%$ minor depression and $23 \%$ depressive symptoms only); and according to the EPIA survey, the 6-month prevalence of generalised anxiety disorder is $4 \%$.
The overall rates for first lifetime contact with mental health out-patient services for all mental disorders has been reported to be 1724.4 per 100000 inhabitants (NCZI, 2009). Almost $27 \%$ of treated mental disorders were classified as neurotic disorders; organic disorders were the second most commonly treated conditions in the out-patient setting (20.5\%), followed by affective disorders (17.5\%) and substance use disorders (12.7\%) in 2008 (NCZI, 2009).

\section{Policy and legislation}

Slovakia has no laws specific to mental healthcare and there is no monitoring of the quality of care. Several independent bodies monitor human rights in general and some nongovernmental organisations address the human rights of those with mental illness (Bražinová et al, 2008).

Slovakia ratified the main human rights instruments in 1992, shortly before the division of Czechoslovakia and the establishment of the Slovak Republic. Mental healthcare falls under the general system of healthcare and is regulated by general healthcare legislation, which reflects much of the international thinking about human rights. An antidiscrimination act, adopted in 2004, bans discrimination on the grounds of health status. The government adopted the Charter of Patients' Rights in 2001 and this has since been promoted through various non-governmental activities. The Charter defines all the rights and entitlements of patients within healthcare delivery as they are stipulated in other 